\title{
Identification of AQP3 and CD24 as biomarkers for carcinogenesis of gastric intestinal metaplasia
}

\author{
Haijian Zhao ${ }^{1,2, *}$, Jianfei Wen ${ }^{1, *}$, Xuqiang Dong ${ }^{1, *}$, Ruji He ${ }^{1, *}$, Cheng Gao ${ }^{1}$, Weiming \\ Zhang ${ }^{3}$, Zhihong Zhang ${ }^{3}$ and Lizong Shen ${ }^{1}$ \\ ${ }^{1}$ Division of Gastrointestinal Surgery, Department of General Surgery, First Affiliated Hospital, Nanjing Medical University, \\ Nanjing 210029, Jiangsu, China \\ ${ }^{2}$ Division of Gastrointestinal Surgery, Department of General Surgery, Affiliated Huai'an Hospital, Xuzhou Medical University, \\ Huai'an 223002, Jiangsu, China \\ ${ }^{3}$ Department of Pathology, First Affiliated Hospital, Nanjing Medical University, Nanjing 210029, Jiangsu, China \\ *These authors have contributed equally to this work \\ Correspondance to: Lizong Shen, email: shenlz@njmu.edu.cn \\ Keywords: gastric intestinal metaplasia, aquaporin 3, CD24, gastric cancer, pathology \\ Received: December 16, $2016 \quad$ Accepted: June 02, $2017 \quad$ Published: June 28, 2017 \\ Copyright: Zhao et al. This is an open-access article distributed under the terms of the Creative Commons Attribution License 3.0 \\ (CC BY 3.0), which permits unrestricted use, distribution, and reproduction in any medium, provided the original author and source \\ are credited.
}

\section{ABSTRACT}

Gastric intestinal metaplasia (GIM) is a precancerous gastric carcinoma (GC) lesion with pivotal roles in carcinogenesis. CD24, LGR5 and Ki67 are expressed in GIM; we previously demonstrated that aquaporin 3 (AQP3) is expressed in goblet cells and is positively correlated with GIM severity. However, the relationships of AQP3 with GIM classification and with other proteins, and their roles in the transition from GIM to gastric carcinoma (GC) remain unknown. Sixteen patients with intestinal-type GC were enrolled in this study. GIM was determined according to the updated Sydney system; GIM classification was determined via HID-AB staining, and AQP3, CD24, LGR5 and Ki67 expression were determined by immunohistochemistry. Type III GIM was more prevalent around the GC and displayed a positive association with GIM severity. CD24 was found in GIM, but LGR5 and Ki67 were found in tissues regardless of GIM. AQP3 expression showed significant correlation to type III GIM. CD24 expression was correlated with the marked GIM and incomplete GIM, while LGR5 expression decreased with GIM aggravation and did not have relationship with classification of GIM. However, Ki67 presented no association with GIM grade or classification. These observations identify AQP3 and CD24 as biomarkers for carcinogenesis of GIM, and may provide a precise strategy for screening at-risk candidates with GIM.

\section{INTRODUCTION}

Gastric carcinoma (GC) remains one of the most common malignances and the third leading cause of cancer-related mortality worldwide [1]. However, the mechanism of GC carcinogenesis still needs to be elucidated. So far, it is well recognized that a multistep process is involved in the progression from normal gastric mucosa to intestinal-type GC, including chronic gastritis, chronic atrophic gastritis, intestinal metaplasia, dysplasia and invasive carcinoma, which was originally proposed by Correa [2, 3]. During this multistep procession, gastric intestinal metaplasia (GIM) is considered to be a precancerous lesion of $\mathrm{GC}$ and to play a pivotal role in GC tumorigenesis $[4,5]$. Based on previous studies $[6$, 7], GIM is classified into three types: type I, type II and type III. According to whether the brush border is welldeveloped or not [6], GIM is classified as complete or incomplete. Type I GIM is complete GIM, and incomplete GIM includes type II and type III GIM. However, the relationship between GIM and GC remains controversial. Most studies agree that the incomplete GIM, especially 
Table 1: Correlation between the type of GIM and the distance from GC

\begin{tabular}{|c|c|c|c|c|c|}
\hline & \multicolumn{3}{|c|}{ Type of GIM } & \multirow{2}{*}{$\chi^{2}$} & \multirow{2}{*}{$\boldsymbol{P}$} \\
\hline & I & II & III & & \\
\hline A & 9 & 10 & 25 & 2.416 & 0.66 \\
\hline B & 6 & 8 & 17 & & \\
\hline $\mathrm{C}$ & 5 & 8 & 8 & & \\
\hline
\end{tabular}

A, B and $\mathrm{C}$ represent $\leq 1 \mathrm{~cm}, 1-2 \mathrm{~cm}$ and $>2 \mathrm{~cm}$ to the margin of the $\mathrm{GC}$ lesion respectively.

Table 2: Correlation between the severity of GIM and the classification of GIM

\begin{tabular}{lccccc}
\hline \multirow{2}{*}{ Type of GIM } & \multicolumn{3}{c}{ Grade of GIM } & \multirow{2}{*}{$\boldsymbol{\chi}^{\mathbf{2}}$} & $\boldsymbol{P}$ \\
\cline { 2 - 5 } & $\mathbf{1}$ & $\mathbf{2}$ & $\mathbf{3}$ & 13.398 & 0.009 \\
I & 7 & 7 & 6 & & \\
II & 2 & 11 & 13 & & \\
III & 6 & 10 & 34 & & \\
\hline
\end{tabular}

type III GIM, has a higher GC risk than the complete GIM [8-10], whereas others believe that incomplete GIM has no association with the high prevalence of GC $[11,12]$.

GIM patients may eventually progress into intestinal-type GC $[3,13]$; however, the incidence remains low $[14,15]$, and direct evidence of gastric carcinogenesis from GIM remains elusive. Some proteins, including the gastric cancer stem cell biomarker CD24 [16], leucinerich-repeat-containing G-protein-coupled receptor 5 (LGR5) [16, 17] and the cell proliferation biomarker Ki67 [18], have been reported to be expressed in GIM tissues, and they are postulated to be involved in the progression from GIM to $\mathrm{GC}[15,19,20]$. However, no further research has been performed to investigate the relationship of these proteins to GIM. Due to the association of GIM with GC, several guidelines have been recommended for the surveillance and screening of these precancerous conditions or lesions [21-23], especially GIM. However, there is no individualized strategy proposed for GIM surveillance in these guidelines, and it seems that no guideline for GIM surveillance has allowed for a patienttailored approach [24].

Previously, we have demonstrated that aquaporin 3 (AQP3), a member of the aquaporin family, was expressed specifically in the membrane of goblet cells, and that AQP3 expression positively correlated with the severity of GIM [25], indicating that AQP3 may play an important role in gastric carcinogenesis from GIM. However, the relationship of AQP3 expression with the GIM classification, its cross-relationship with other proteins, i.e., CD24, LGR5 and Ki67, and their potential roles in gastric tumorigenesis from GIM remain unknown. In this study, we further refined the classification of GIM in the non-cancerous gastric mucosa adjacent to GC, as well as documenting the expression of AQP3, CD24, LGR5 and $\mathrm{Ki} 67$ in these tissues. We found that type III GIM was a more prevalent event in tissues around GC and correlated with marked GIM. We also showed that AQP3 and CD24 were expressed in non-cancerous mucosa tissues with GIM, while LGR5 and Ki67 were expressed in mucosa tissues regardless of the presence of GIM. AQP3 showed significant correlation to type III GIM, and CD24 exhibited remarkable association with the marked GIM and the incomplete GIM. In addition, LGR5 expression in GIM showed remarkable correlation with Ki67. These observations further establish the role of AQP3 in the gastric tumorigenesis, and suggest that CD24, rather than LGR5 and Ki67, may be involved in this progression. This study identifies AQP3 and CD24 as biomarkers for carcinogenesis of GIM, and improves our understanding of the mechanism of carcinogenesis from GIM to GC and may provide a precise strategy for screening at-risk candidates with GIM.

\section{RESULTS}

\section{Type III GIM correlates with the severity of GIM}

Previously, we reported that the incidence of GIM was $50 \%$ in 192 regions of the non-cancerous gastric mucosa tissues around the GC. We also showed that the incidence and severity of GIM was correlated with the distance from the GC, and GIM became more prevalent and more severe with increasing proximity to GC lesions. These data suggest an association between GIM and 
gastric carcinogenesis [25]. In this study, we identified the classification of GIM around GC. Among the 96 regions of mucosa tissues with GIM around GC, type III GIM occupied 52.1\% (50/96), while type I GIM and type II GIM occupied $20.8 \%$ (20/96) and 27.1\% (26/96), respectively, indicating that type III GIM was more prevalent in tissues adjacent to $\mathrm{GC}\left(\chi^{2}=23.625, P<0.001\right)$.

We then evaluated the correlation between the type of GIM with the distance from the GC, finding that there were no significant differences (Table $1 ; \chi^{2}=2.416$, $P=0.66$ ). We further investigated the relationship between GIM type and GIM severity, and found that marked GIM was associated with type III GIM (Table $2 ; \chi^{2}=13.398$, $P=0.009$ ). These results are consistent with previous studies [8], which indicated that incomplete GIM, especially type III, has a higher GC risk than complete GIM.

\section{AQP3, CD24, LGR5 and Ki67 expression in GIM and their correlations with GIM grade and classification}

As reported previously [25], AQP3 was expressed specifically in the membrane of goblet cells in GIM, and AQP3 expression positively correlated with the severity of GIM $(P<0.001)$, but AQP3 expression had no significant correlation with the distance from $\mathrm{GC}$ lesions $(P=0.376)$.

In this study, we further investigated CD24, LGR5 and Ki67 expression in GIM. Unlike AQP3, these proteins were not specifically expressed in goblet cells. CD24 was expressed in the regions with GIM and was mainly located in the membrane and cytoplasm of columnar epithelial cells (Figure 1A), and its prevalence was $28.13 \%$ (27/96). CD24 was not found in goblet cells nor in tissues without GIM (Figure 1). LGR5 was found in tissues regardless of the presence of GIM, and the prevalence of LGR5 was $45.83 \%(44 / 96)$ in the regions without GIM (Figure 2A) and $20.83 \%(20 / 96)$ in the regions with GIM (Figure 2C). LGR5 was mainly located in the membrane of columnar epithelial cells and was not found in goblet cells. Like
LGR5, Ki67 was also found in tissues despite the presence of GIM, and the prevalence of Ki67 was 40.62\% (39/96) in the regions without GIM (Figure 3A) and 20.83\% (20/96) in the regions with GIM (Figure 3C). Ki67 was mainly located in the nucleus of columnar epithelial cells and was not found in goblet cells. There was no significant correlation found between the expression of these proteins and distance from the GC (Table 3; $\mathrm{r}=-0.076, P=0.461$ for CD24; $\mathrm{r}=-0.078, P=0.448$ for LGR5; $\mathrm{r}=-0.142, P=0.168$ for Ki67), which was similar to the results of AQP3 [25].

We were more interested in the associations of AQP3, CD24, LGR5 and Ki67 with the grade and classification of GIM. In addition to the association with the severity of GIM, AQP3 showed significant correlation to the classification of GIM (Table $4 ; \chi^{2}=7.203, P=0.027$ ) with the prevalence of $45 \%, 65.38 \%$ and $78 \%$ in type I, type II and type III GIM, respectively. As shown in Table $5, \mathrm{CD} 24$ expression had a remarkable positive association with the severity of GIM $(P<0.001)$, with this association being most prevalent in marked GIM (35.85\%), while LGR5 also showed significant correlation with the grade of GIM $(P=0.043)$ and LGR5 expression decreased with GIM aggravation. Ki67 was not found to correlate to the severity of $\operatorname{GIM}(P=0.126)$. Furthermore, there was also a significant association of CD24 $(P=0.034)$ with the type of GIM, with the most prevalence in type II GIM (46.15\%), but LGR5 and Ki67 exhibited no association with GIM type (Table 6; $P=0.321$ and $P=0.204$, respectively). Together, these data show that AQP3 and CD24, rather than LGR5 and Ki67, were associated with the marked GIM and the incomplete GIM.

\section{The cross-relationship of AQP3, CD24, LGR5 and Ki67 in GIM}

We next evaluated the cross-relationship of AQP3, CD24, LGR5 and Ki67 in GIM. As shown in Table 7, AQP3 expression in GIM was not associated with CD24 $\left(\chi^{2}=0.122, P=0.727\right)$, LGR5 $\left(\chi^{2}=0.061, P=0.805\right)$ or Ki67 $\left(\chi^{2}=0.061, P=0.805\right)$; CD24 expression in GIM
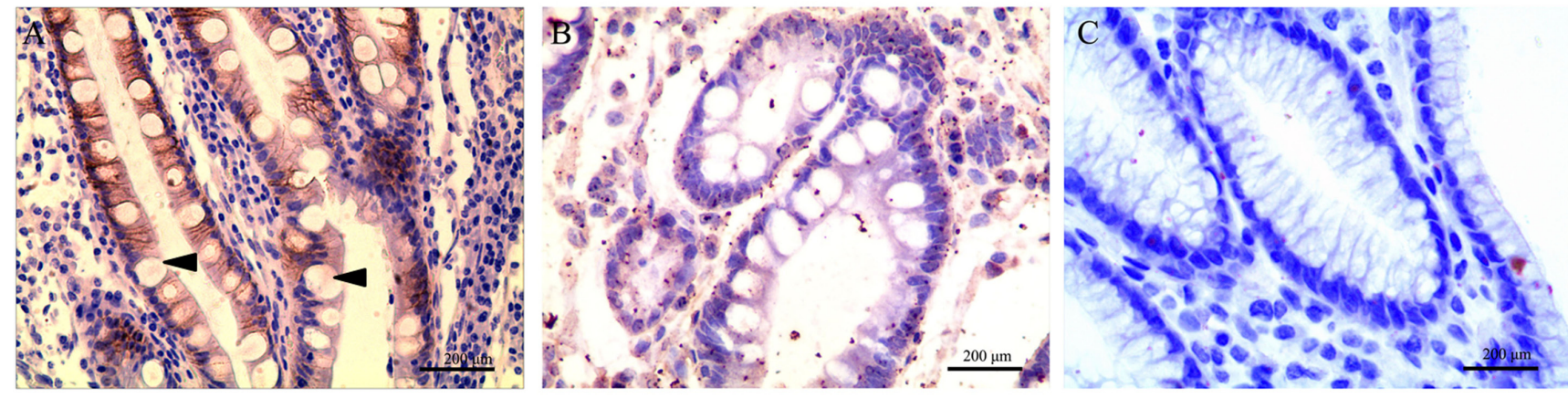

Figure 1: CD24 expression in gastric intestinal metaplasia (GIM). (A) Strong CD24 immunoreactivity in GIM; (B) negative CD24 expression in GIM; (C) CD24 was not found in tissues without GIM. CD24 was mainly located in the membrane and cytoplasm of columnar epithelial cells and was not expressed in goblet cells (arrow). Original magnification: 400×. 
exhibited no significant association with LGR5 $\left(\chi^{2}=1.762\right.$, $P=0.184)$ or Ki67 $\left(\chi^{2}=3.559, P=0.059\right)$. However, LGR5 expression in GIM showed remarkable correlation with $\operatorname{Ki67}\left(\chi^{2}=8.946, P=0.003\right)$.

\section{DISCUSSION}

Several epidemiological surveys have demonstrated that GIM is closely related to the development of GC [8-10]. Compared with patients with type I GIM and people with normal gastric mucosa, patients with type III GIM have a 4-11-fold increased risk of developing GC [26]. However, the pathological evidence is lacking with regard to the association between GIM and GC, and the underlying mechanisms remian to be elucidated. In this study, type III GIM was found to be a more common event than type I or type II GIM in the non-cancerous mucosa around $\mathrm{GC}$, although there was no significant difference concerning the relationship of GIM type with the distance from GC lesions. Importantly, we also revealed that type
III GIM displayed a remarkable positive association to the severity of GIM in the non-cancerous mucosa tissues around the cancer. These findings provide a pathological link between GIM and GC, especially type III GIM and GC.

However, the mechanism underlying the progression of GIM to GC has not been identified. CD24, LGR5, $\mathrm{Ki} 67$ and other proteins have been demonstrated to be expressed in GIM tissues [15, 19, 20], but their roles in this process need to be further investigated. Both CD24 and LGR5 are gastric cancer stem cell biomarkers expressed simultaneously in gastric cancer tissues [16], whereas $\mathrm{Ki} 67$ is involved in the formation of gastric adenocarcinoma [27]. This study investigated the expression of these proteins in GIM in addition to AQP3, and their significance in GIM was evaluated.

Aquaporins (AQPs) are a family of integral membrane proteins that transport water and, in some cases, water and glycerol ("aquaglyceroporins") [28, 29]. We previously demonstrated that AQP3 is overexpressed
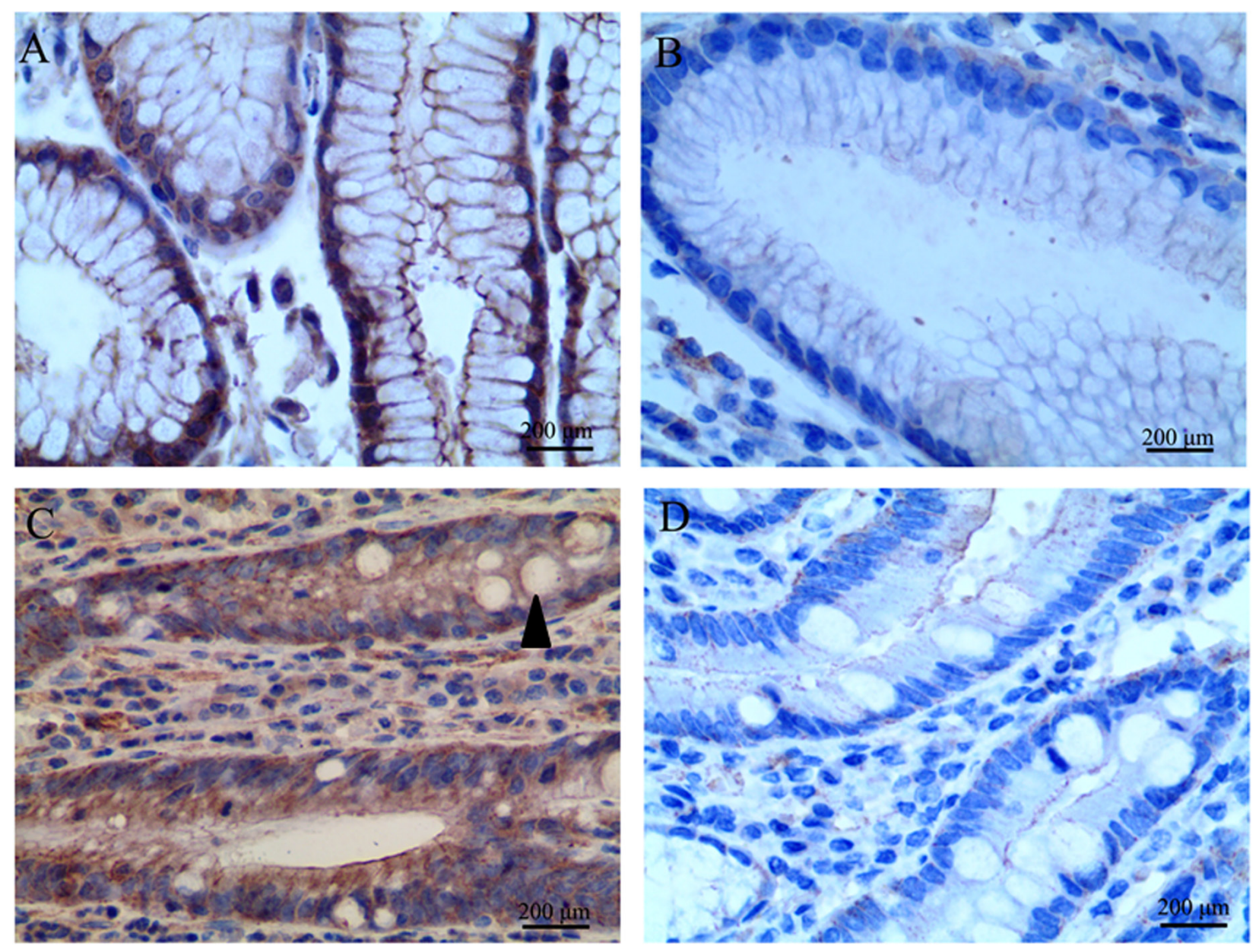

Figure 2: LGR5 expression in tissues adjacent to gastric carcinoma (GC). LGR5 expression was found in tissues regardless of the presence of GIM. (A) Positive LGR5 expression in tissues without GIM; (B) negative LGR5 in tissues without GIM; (C) strong LGR5 immunoreactivity in GIM; (D) negative LGR5 in GIM. LGR5 was mainly located in the membrane of columnar epithelial cells, and was not found in goblet cells (arrow). Original magnification: 400×. 
Table 3: Correlation of CD24, LGR5, Ki67 immunoreactivity with the distance from GC

\begin{tabular}{|c|c|c|c|c|c|c|c|c|c|c|c|c|}
\hline & \multicolumn{4}{|c|}{ CD24 } & \multicolumn{4}{|c|}{ LGR5 } & \multicolumn{4}{|c|}{ Ki67 } \\
\hline & Positive & Negative & $\mathbf{r}$ & $P$ & Positive & Negative & $\mathbf{r}$ & $P$ & Positive & Negative & $\mathbf{r}$ & $P$ \\
\hline A & 14 & 30 & -0.076 & 0.461 & 11 & 33 & -0.078 & 0.448 & 12 & 32 & -0.142 & 0.168 \\
\hline B & 8 & 23 & & & 5 & 26 & & & 5 & 26 & & \\
\hline $\mathrm{C}$ & 5 & 16 & & & 4 & 17 & & & 3 & 18 & & \\
\hline
\end{tabular}

A, B and $\mathrm{C}$ represent $\leq 1 \mathrm{~cm}, 1-2 \mathrm{~cm}$ and $>2 \mathrm{~cm}$ to the margin of the $\mathrm{GC}$ lesion respectively.

in GC tissues and that its expression is associated with increased histological classification, lymph node metastasis and lymphovascular invasion [30, 31]. AQP3 upregulation promotes the proliferation and migration of GC cells via promoting epithelial-mesenchymal transition [32] and stem-like properties [33], suggesting that AQP3 is involved in the carcinogenesis and progression of GC. Interestingly, AQP3 was found to be expressed differentially in the membrane of goblet cells, and AQP3 immunoreactivity was identified more frequently in severe GIM areas [25]. In this study, AQP3 expression showed significant correlation to type III GIM. Collectively, these results indicated that AQP3 is expressed in GIM, and correlates with the most severe type of GIM, which supports the critical role of AQP3 in gastric inflammatory carcinoma transformation proposed in our previous study [25].

Our present study showed that CD24, LGR5 and Ki67 were also expressed in non-cancerous tissues around the GC. CD24 was expressed only in tissues with GIM, and its prevalence was rather low, while LGR5 and Ki67 were expressed in tissues regardless of the
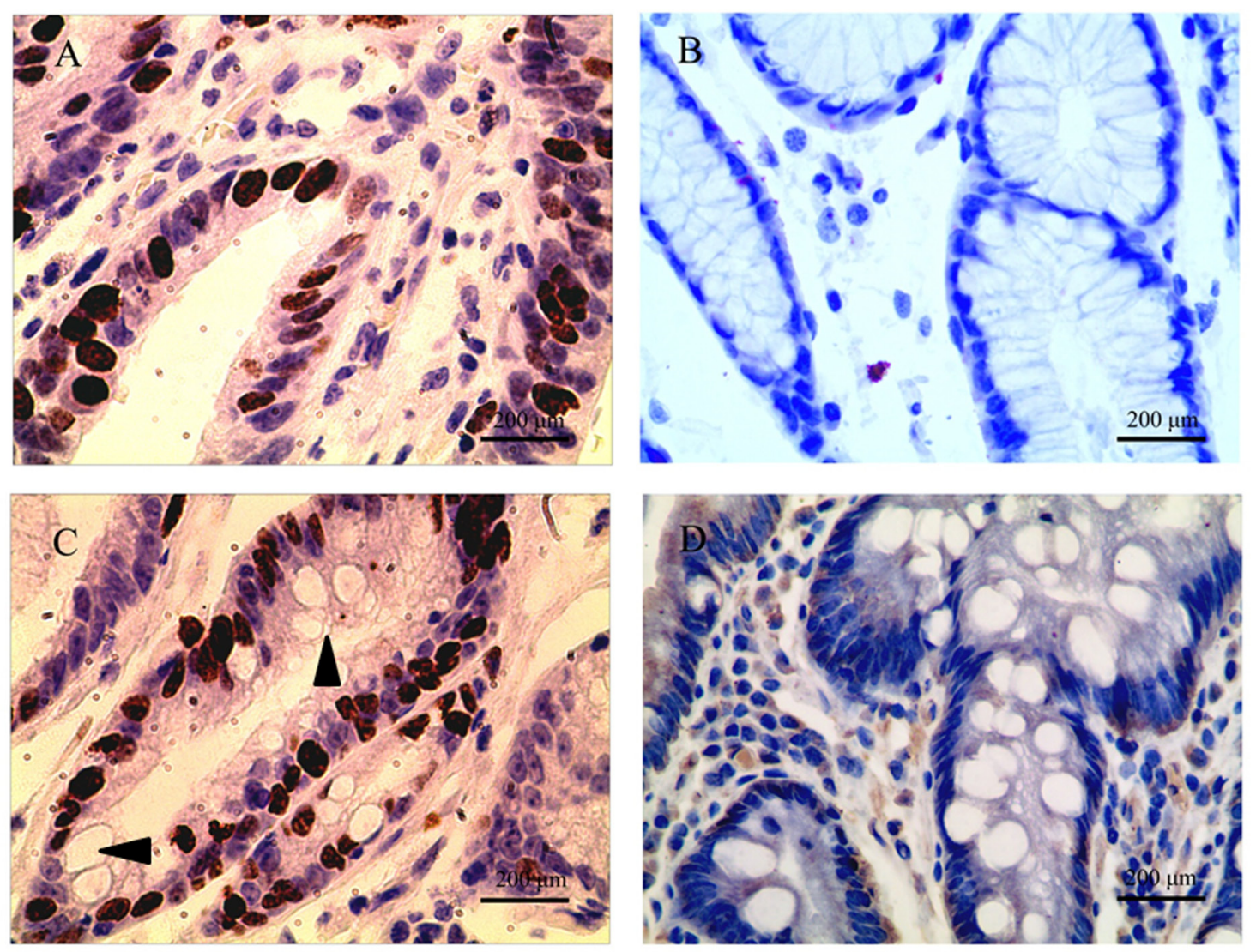

Figure 3: Ki67 expression in tissues adjacent to gastric carcinoma (GC). Ki67 expression was also found in tissues regardless of the presence of GIM. (A) Positive Ki67 expression in tissues without GIM; (B) negative Ki67 in tissues without GIM; (C) strong Ki67 immunoreactivity in GIM; (D) negative Ki67 in GIM. Ki67 was mainly located in the nucleus of columnar epithelial cells, and was not found in goblet cells (arrow). Original magnification: 400×. 
Table 4: Relationship of AQP3 immunoreactivity with the subtypes of GIM

\begin{tabular}{|c|c|c|c|c|c|}
\hline \multirow{2}{*}{ AQP3 immunoreactivity } & \multicolumn{3}{|c|}{ Type of GIM } & \multirow{2}{*}{$\chi^{2}$} & \multirow{2}{*}{$\boldsymbol{P}$} \\
\hline & I & II & III & & \\
\hline Positive & 9 & 17 & 39 & 7.203 & 0.027 \\
\hline Negative & 11 & 9 & 11 & & \\
\hline
\end{tabular}

Table 5: Correlation between CD24, LGR5, Ki67 expression and the grade of GIM

\begin{tabular}{|c|c|c|c|c|c|c|c|c|c|c|c|c|}
\hline \multirow{2}{*}{ GIM grade } & \multicolumn{4}{|c|}{ CD24 } & \multicolumn{4}{|c|}{ LGR5 } & \multicolumn{4}{|c|}{ Ki67 } \\
\hline & Positive & Negative & $\mathbf{r}$ & $P$ & Positive & Negative & $\mathbf{r}$ & $P$ & Positive & Negative & $\mathbf{r}$ & $P$ \\
\hline 0 & 0 & 96 & 0.442 & $<0.001$ & 44 & 96 & -0.132 & 0.043 & 39 & 96 & -0.101 & 0.126 \\
\hline 1 & 2 & 13 & & & 3 & 12 & & & 3 & 12 & & \\
\hline 2 & 6 & 22 & & & 9 & 19 & & & 8 & 20 & & \\
\hline 3 & 19 & 34 & & & 8 & 45 & & & 9 & 44 & & \\
\hline
\end{tabular}

Table 6: Relationship of CD24, LGR5, Ki67 immunoreactivity with the classification of GIM

\begin{tabular}{|c|c|c|c|c|c|c|c|c|c|c|c|c|}
\hline \multirow{2}{*}{ Type of GIM } & \multicolumn{4}{|c|}{ CD24 } & \multicolumn{4}{|c|}{ LGR5 } & \multicolumn{4}{|c|}{ Ki67 } \\
\hline & Positive & Negative & $\chi^{2}$ & $P$ & Positive & Negative & $\chi^{2}$ & $P$ & Positive & Negative & $\chi^{2}$ & $P$ \\
\hline I & 6 & 14 & 6.751 & 0.034 & 4 & 16 & 2.273 & 0.321 & 7 & 13 & 3.182 & 0.204 \\
\hline II & 12 & 14 & & & 8 & 18 & & & 5 & 21 & & \\
\hline III & 9 & 41 & & & 8 & 42 & & & 8 & 42 & & \\
\hline
\end{tabular}

presence of GIM, and they were more common in tissues without GIM than that in tissues with GIM. Importantly, CD24 expression was found to be associated with type II and type III GIM. LGR5 expression decreased with GIM aggravation, but showed no correlation with GIM classification. Ki67 did not present any association with the grade and classification of GIM, and both LGR5 and Ki67 were not expressed in goblet cells. To our knowledge, AQP3 is the first and the only protein found to be expressed specifically in the membrane of goblet cells. These results indicate that AQP3 and CD24, rather than LGR5 and Ki67, may be involved in the carcinogenesis of GC from GIM.

CD24, an adhesive molecule and one of molecular biomarkers of cancer stem cells, is associated with cancer cell proliferation and migration [34, 35], and cells with CD24 expression may be the cancer-initiating cells that promote tumor migration and metastasis [36-38]. Wang and his colleagues reported that CD24 expression increased gradually in samples of normal gastric mucosa, non-atrophic chronic gastritis, chronic atrophic gastritis (CAG), CAG with intestinal metaplasia, dysplasia and GC [19]. Our results were consistent with this report and further support the potential role of CD24 in gastric inflammatory carcinoma transformation.

LGR5, identified as one of the biomarkers of gastric cancer stem cells, is associated with the carcinogenesis of gastric cancer [16, 17]. RNA in situ hybridization revealed the overexpression of LGR5 in intestinal metaplasia in the gastric antrum of mice [39]. Lineage tracing has confirmed cells with LGR5 expression to be the initiating cells of gastric adenomas in animal models [40-42]. However, such techniques are not suitable for studying human gastric cancer $[43,44]$. Gastric stem cells with LGR5 expression were only found in the antrum of adult mice, where they drive self-renewal in the stomach and can be used to build long-lived gastric units in vitro [40, 45]. Ki67, a nuclear proliferation-associated antigen, is increased in many tumors and correlates with cell proliferation [18]. Studies have confirmed Ki67 expression in low grade adenoma, high grade adenoma and intestinaltype gastric adenocarcinoma [27], and its expression is increased in the transformation from GIM to GC [20]. Zheng et al reported that Ki67 expression was significantly higher in gastric carcinomas than in type I GIM, while no significant differences in Ki67 expression were observed 
Table 7: The cross-relationship of AQP3, CD24, LGR5 and Ki67 in GIM

\begin{tabular}{|c|c|c|c|c|c|c|c|c|c|c|c|c|}
\hline \multirow{2}{*}{ AQP3 } & \multicolumn{4}{|c|}{ CD24 } & \multicolumn{4}{|c|}{ LGR5 } & \multicolumn{4}{|c|}{ Ki67 } \\
\hline & Positive & Negative & $\chi^{2}$ & $P$ & Positive & Negative & $\chi^{2}$ & $P$ & Positive & Negative & $\chi^{2}$ & $P$ \\
\hline Positive & 19 & 46 & 0.122 & 0.727 & 14 & 51 & 0.061 & 0.805 & 14 & 51 & 0.061 & 0.805 \\
\hline Negative & 8 & 23 & & & 6 & 25 & & & 6 & 25 & & \\
\hline \multirow{2}{*}{ CD24 } & \multicolumn{6}{|c|}{ Ki67 } & \multicolumn{6}{|c|}{ LGR5 } \\
\hline & & sitive & Negativ & & $\chi^{2}$ & $P$ & & sitive & Negative & $\chi^{2}$ & & $P$ \\
\hline Positive & & 9 & 18 & & 3.559 & 0.059 & & 8 & 19 & 1.762 & & 0.184 \\
\hline Negative & & 11 & 58 & & & & & 12 & 57 & & & \\
\hline \multirow{2}{*}{ Ki67 } & & & \multicolumn{4}{|c|}{ LGR5 } & & & \multirow{2}{*}{$\chi^{2}$} & \multirow{2}{*}{\multicolumn{3}{|c|}{$P$}} \\
\hline & & & \multicolumn{2}{|c|}{ Positive } & & \multicolumn{3}{|l|}{ Negative } & & & & \\
\hline Positive & & & \multicolumn{2}{|l|}{9} & & \multicolumn{2}{|l|}{11} & & \multirow[t]{2}{*}{8.946} & \multicolumn{3}{|c|}{0.003} \\
\hline Negative & & & \multicolumn{2}{|l|}{11} & & \multicolumn{3}{|l|}{65} & & & & \\
\hline
\end{tabular}

among type II GIM, type III GIM and GC [46]. However, our study showed that $\mathrm{Ki} 67$ was expressed in adjacent mucosa tissues around the GC, but did not support their roles in carcinogenesis of GC from GIM, which remains to be further investigated.

Although AQP3 has been demonstrated to promote GC cell proliferation and the stem-like properties of human GC cells by activating the Wnt/GSK-3 $\beta / \beta$-catenin signaling pathway [33], AQP3 expression in GIM was not found to have a relationship with CD24, LGR5 or Ki67 expression. We hypothesize that AQP3 may have different effects on non-cancerous cells from cancerous cells. In addition, the significant association of LGR5 and Ki67 in GIM needs to be investigated in the future.

At present, there is a paucity of recognized consensus on how to perform a follow-up for GIM due to the lack of convincing indicators for predicting the risk of transformation from GIM into GC, although the role of endoscopy in the surveillance of premalignant conditions of the upper GI tract (ASGE guideline) [21], and management of precancerous conditions and lesions in the stomach (MAPS) (European guideline) [23] have been recommended. The ASGE guideline does not recommend endoscopic surveillance for GIM uniformly; however, it agrees that patients at increased risk for GC due to ethnic background or family history might benefit from surveillance, and that endoscopic surveillance should incorporate a topographic mapping of the entire stomach. The MAPS recommends that endoscopic surveillance, every 3 years after diagnosis, should be offered to patients with extensive intestinal metaplasia, but it does not recommend endoscopic surveillance for patients with mild to moderate intestinal metaplasia restricted to the antrum. The Asia Pacific


Figure 4: The classification of gastric intestinal metaplasia (GIM) with high iron diamine-alcian blue staining (HIDAB). (A) Type I GIM, sialomucin in goblet cells stained blue by HID-AB; (B) type II GIM, sialomucins and occasionally sulfomucins (black by HID-AB stain), or a mixture of these two mucins in goblet cells (stained brown/purple by HID-AB stain); (C) type III GIM, sulfomucins secreted in columnar intermediate cells, and sialomucins and/or sulfomucins secreted in goblet cells. Original magnification: $400 \times$. 
Working Group on Gastric Cancer [47] recommends the combined use of $H$. pylori serology, and serum gastrin-17 and pepsinogen concentrations [22], and the presence of histological intestinal metaplasia to screen gastric cancer [48]. However, these guidelines do not provide a patient-tailored approach for GIM surveillance. This study, as well as our previous report [25], provide the initial pathological evidence for the association of GIM severity and classification with gastric carcinogenesis, and show that AQP3 or CD24 expression correlates with the marked GIM and the incomplete GIM. We conceive that GIM severity and classification, as well as AQP3 or CD24 expression, should be introduced to surveillance programs for GIM. During surveillance, attention should be paid to the incomplete GIM and/or marked GIM, especially with AQP3 and/or CD24 expression. Thus, the high-risk patients will be identified and an individualized strategy can be implemented. As this is a preliminary study, a prospective and randomized clinical trial is needed to evaluate the feasibility and effectiveness of this approach.

\section{MATERIALS AND METHODS}

\section{Human gastric tissue specimens}

All human gastric tissue specimens of noncancerous gastric mucosa tissues adjacent to GC presented in our previous study [25] were introduced in this study. These specimens came from 16 patients (median age: $62.25 \pm 12.40$ years; range: $44-86$ years) diagnosed with intestinal-type gastric adenocarcinoma located in the lesser curve of the antrum between September and November 2014 at the Department of General Surgery, First Affiliated Hospital, Nanjing Medical University.

The gastric mucosal rolls in the four directions of 3-, 6-, 9- and 12-o'clock around the GC lesions, which corresponded to the posterior wall, pylorus, anterior wall and cardiac directions, respectively, were used in this study. We named this technique as "gastric mucosal sausage roll" [25]. The transverse sections of these rolls were obtained to evaluate GIM and immunoreactivity of AQP3, CD24, LGR5 and Ki67 by two experienced gastrointestinal pathologists that were blinded to the study. Each section was divided into three parts, $\mathrm{A}(\leq 1 \mathrm{~cm})$, B $(1-2 \mathrm{~cm})$ and $\mathrm{C}(>2 \mathrm{~cm})$, according to the distance to the margin of the GC lesion. The informed consent was obtained from all patients, and the protocol was approved by the Nanjing Medical University Institutional Review Board. This study was also in compliance with the Declaration of Helsinki.

\section{GIM grading and classification}

Sections (5- $\mu \mathrm{m}$-thick) were deparaffinized and stained with hematoxylin and eosin (HE). The presence of goblet cells indicated presence of GIM. According to the updated Sydney system [49], GIM were graded as absent, mild, moderate or marked (grades 0-3, respectively).

High iron diamine-alcian blue (HID-AB) staining was performed for GIM classification. Type I GIM presented sialomucin in goblet cells stained blue by HID-AB (Figure 4A). Type II GIM showed sialomucins and occasionally sulfomucins (black by HID-AB stain), or a mixture of these two mucins in goblet cells (stained brown/purple by HID-AB stain) (Figure 4B). Type III GIM presented sulfomucins secreted in columnar cells, and sialomucins and/or sulfomucins secreted in goblet cells (Figure 4C).

\section{Immunohistochemical assay for AQP3, CD24, LGR5 and Ki67 expression}

AQP3, CD24, LGR5 and Ki67 expression in goblet cells was determined by immunohistochemistry (IHC), as described previously $[25,50]$. The polyclonal rabbit anti-AQP3 antibody was obtained from Santa Cruz Biotechnology (Santa Cruz, CA, USA). The monoclonal mouse anti-CD24 and polyclonal rabbit anti-LGR5 antibodies were obtained from Abcam Biotechnology (Cambridge, UK) and the monoclonal rabbit anti-Ki67 antibody was from Fuzhou Maixin Biotechnology (Fuzhou, China). Two pathologists scored protein expression as the percentage of positive cells (scale $0 \%-100 \%$ ) with a staining intensity from $0-3+$. Positive IHC expression was defined as $>25 \%$ staining with an intensity of $2-3+$.

\section{Statistical analysis}

All statistical analyses were performed with SPSS version 17.0 (SPSS Inc., Chicago, IL, USA). The association between various clinicopathological parameters was examined via Pearson's chi-square test and Spearman's rank correlation. $P<0.05$ was considered statistically significant.

\section{ACKNOWLEDGMENTS}

The authors thank Prof. Wu Wenxi for critical suggestion.

\section{CONFLICTS OF INTEREST}

The authors declare they have no conflicts of interest.

\section{GRANT SUPPORT}

This project was funded by the National Natural Science Foundation of China (Grant No. 81272711), the Priority Academic Program Development of Jiangsu Higher Education Institutions (PAPD, JX10231801), and the Key Medical Talent Project of Jiangsu Province (ZDRCA2016014). 


\section{REFERENCES}

1. Ferlay J, Soerjomataram I, Dikshit R, Eser S, Mathers C, Rebelo M, Parkin DM, Forman D, Bray F. Cancer incidence and mortality worldwide: sources, methods and major patterns in GLOBOCAN 2012. Int J Cancer. 2015; 136:E359-E386.

2. Correa P. A human model of gastric carcinogenesis. Cancer Res. 1988; 48:3554-3560.

3. Correa P. Human gastric carcinogenesis: a multistep and multifactorial process-First American Cancer Society Award Lecture on Cancer Epidemiology and Prevention. Cancer Res. 1992; 52:6735-6740.

4. Zullo A, Hassan C, Romiti A, Giusto M, Guerriero C, Lorenzetti R, Campo SM, Tomao S. Follow-up of intestinal metaplasia in the stomach: when, how and why. World J Gastrointest Oncol. 2012; 4:30-36.

5. Lee TY, Wang RC, Lee YC, Lin JT, Ho HJ, Hsieh MC, $\mathrm{Wu} \mathrm{CY}$. The incidence of gastric adenocarcinoma among patients with gastric intestinal metaplasia: a long-term cohort study. J Clin Gastroenterol. 2016; 50:532-537.

6. Correa P, Piazuelo MB, Wilson KT. Pathology of gastric intestinal metaplasia: clinical implications. Am J Gastroenterol. 2010; 105:493-498.

7. Li Y, Chang X, Zhou W, Xiao Y, Nakatsuka LN, Chen J, Lauwers GY. Gastric intestinal metaplasia with basal gland atypia: a morphological and biologic evaluation in a large Chinese cohort. Hum Pathol. 2013; 44:578-590.

8. González CA, Pardo ML, Liso JM, Alonso P, Bonet C, Garcia RM, Sala N, Capella G, Sanz-Anquela JM. Gastric cancer occurrence in preneoplastic lesions: a long-term follow-up in a high-risk area in Spain. Int J Cancer. 2010; 127:2654-2660.

9. Rokkas T, Filipe MI, Sladen GE. Detection of an increased incidence of early gastric cancer in patients with intestinal metaplasia type III who are closely followed up. Gut. 1991; 32:1110-1113.

10. Olmez S, Aslan M, Erten R, Sayar S, Bayram I. The prevalence of gastric intestinal metaplasia and distribution of Helicobacter pylori infection, atrophy, dysplasia, and cancer in its subtypes. Gastroenterol Res Pract. 2015; 2015:434039.

11. El-Zimaity HM, Ramchatesingh J, Saeed MA, Graham DY. Gastric intestinal metaplasia: subtypes and natural history. J Clin Pathol. 2001; 54:679-683.

12. Kang KP, Lee HS, Kim N, Kang HM, Park YS, Lee DH, Choe G, Kim JS, Jung HC, Song IS. Role of intestinal metaplasia subtyping in the risk of gastric cancer in Korea. J Gastroenterol Hepatol. 2009; 24:140-148.

13. Bronner MP. Gastric cancer and intestinal metaplasia. Hum Pathol. 1999; 30:733.

14. de Vries AC, van Grieken NC, Looman CW, Casparie MK, de Vries E, Meijer GA, Kuipers EJ. Gastric cancer risk in patients with premalignant gastric lesions: a nationwide cohort study in the Netherlands. Gastroenterology. 2008; 134:945-952.

15. Zheng ZX, Sun Y, Bu ZD, Zhang LH, Li ZY, Wu AW, Wu XJ, Wang XH, Cheng XJ, Xing XF, Du H, Ji JF. Intestinal stem cell marker LGR5 expression during gastric carcinogenesis. World J Gastroenterol. 2013; 19:8714-8721.

16. Rassouli FB, Matin MM, Saeinasab M. Cancer stem cells in human digestive tract malignancies. Tumour Biol. 2016; 37:7-21.

17. Wang Z, Liu C. Lgr5-positive cells are cancer-stem-celllike cells in gastric cancer. Cell Physiol Biochem. 2015; 36:2447-2455.

18. Huang G, Chen S, Wang D, Wang R, Lin L, Chen S, Wang L, Huang Q. High Ki67 expression has prognostic value in surgically-resected T3 gastric adenocarcinoma. Clin Lab. 2016; 62:141-153.

19. Wang YC, Wang JL, Kong X, Sun TT, Chen HY, Hong J, Fang JY. CD24 mediates gastric carcinogenesis and promotes gastric cancer progression via STAT3 activation. Apoptosis. 2014; 19:643-656.

20. Feng XS, Wang YF, Hao SG, Ru Y, Gao SG, Wang LD. Expression of Das-1, Ki67 and sulfuric proteins in gastric cardia adenocarcinoma and intestinal metaplasia lesions. Exp Ther Med. 2013; 5:1555-1558.

21. Hirota WK, Zuckerman MJ, Adler DG, Davila RE, Egan J, Leighton JA, Qureshi WA, Rajan E, Fanelli R, WheelerHarbaugh J, Baron TH, Faigel DO. ASGE guideline: the role of endoscopy in the surveillance of premalignant conditions of the upper GI tract. Gastrointest Endosc. 2006; 63:570-580.

22. Watabe H, Mitsushima T, Yamaji Y, Okamoto M, Wada R, Kokubo T, Doi H, Yoshida H, Kawabe T, Omata M. Predicting the development of gastric cancer from combining Helicobacter pylori antibodies and serum pepsinogen status: a prospective endoscopic cohort study. Gut. 2005; 54:764-768.

23. Dinis-Ribeiro M, Areia M, de Vries AC, Marcos-Pinto R, Monteiro-Soares M, O'Connor A, Pereira C, PimentelNunes P, Correia R, Ensari A, Dumonceau JM, Machado JC, Macedo G, et al. Management of precancerous conditions and lesions in the stomach (MAPS): guideline from the European Society of Gastrointestinal Endoscopy (ESGE), European Helicobacter Study Group (EHSG), European Society of Pathology (ESP), and the Sociedade Portuguesa de Endoscopia Digestiva (SPED). Endoscopy. 2012; 44:74-94.

24. Zullo A, Hassan C, Repici A, Annibale B. Intestinal metaplasia surveillance: searching for the road-map. World J Gastroenterol. 2013; 19:1523-1526.

25. Zhao H, Yang X, Zhou Y, Zhang W, Wang Y, Wen J, Zhang Z, Shen L. Potential role of aquaporin 3 in gastric intestinal metaplasia. Oncotarget. 2015; 6:38926-38933. doi: 10.18632/oncotarget.5370.

26. Gonzalez CA, Sanz-Anquela JM, Gisbert JP, Correa P. Utility of subtyping intestinal metaplasia as marker of 
gastric cancer risk. A review of the evidence. Int J Cancer. 2013; 133:1023-1032.

27. Shomori K, Nishihara K, Tamura T, Tatebe S, Horie Y, Nosaka K, Haruki T, Hamamoto Y, Shiomi T, Nakabayashi M, Ito H. Geminin, Ki67, and minichromosome maintenance 2 in gastric hyperplastic polyps, adenomas, and intestinal-type carcinomas: pathobiological significance. Gastric Cancer. 2010; 13:177-185.

28. Agre P. The aquaporin water channels. Proc Am Thorac Soc. 2006; 3:5-13.

29. Magni F, Sarto C, Ticozzi D, Soldi M, Bosso N, Mocarelli P, Kienle MG. Proteomic knowledge of human aquaporins. Proteomics. 2006; 6:5637-5649.

30. Shen L, Zhu Z, Huang Y, Shu Y, Sun M, Xu H, Zhang G, Guo R, Wei W, Wu W. Expression profile of multiple aquaporins in human gastric carcinoma and its clinical significance. Biomed Pharmacother. 2010; 64:313-318.

31. Wang J, Gui Z, Deng L, Sun M, Guo R, Zhang W, Shen L. c-Met upregulates aquaporin 3 expression in human gastric carcinoma cells via the ERK signalling pathway. Cancer Lett. 2012; 319:109-117.

32. Chen J, Wang T, Zhou YC, Gao F, Zhang ZH, Xu H, Wang SL, Shen LZ. Aquaporin 3 promotes epithelialmesenchymal transition in gastric cancer. J Exp Clin Cancer Res. 2014; 33:38.

33. Zhou Y, Wang Y, Wen J, Zhao H, Dong X, Zhang Z, Wang $\mathrm{S}$, Shen L. Aquaporin 3 promotes the stem-like properties of gastric cancer cells via Wnt/GSK-3beta/beta-catenin pathway. Oncotarget. 2016; 7:16529-16541. doi: 10.18632/ oncotarget.7664.

34. Pei Z, Zhu G, Huo X, Gao L, Liao S, He J, Long Y, Yi H, Xiao S, Yi W, Chen P, Li X, Li G, Zhou Y. CD24 promotes the proliferation and inhibits the apoptosis of cervical cancer cells in vitro. Oncol Rep. 2016; 35:1593-1601.

35. Kwon MJ, Han J, Seo JH, Song K, Jeong HM, Choi JS, Kim YJ, Lee SH, Choi YL, Shin YK. CD24 overexpression is associated with poor prognosis in Luminal A and triplenegative breast cancer. PLoS One. 2015; 10:e139112.

36. Bozorgi A, Khazaei M, Khazaei MR. New findings on breast cancer stem cells: a review. J Breast Cancer. 2015; 18:303-312.

37. Rostoker R, Jayaprakash AD, Sachidanandam R, LeRoith D. Deep sequencing of mRNA in CD24(-) and CD24(+) mammary carcinoma Mvt1 cell line. Genom Data. 2015; 5:399-401.

38. Salaria S, Means A, Revetta F, Idrees K, Liu E, Shi C. Expression of CD24, a stem cell marker, in pancreatic and small intestinal neuroendocrine tumors. Am J Clin Pathol. 2015 ; 144:642-648.

39. Jang BG, Lee BL, Kim WH. Distribution of LGR5+ cells and associated implications during the early stage of gastric tumorigenesis. PLoS One. 2013; 8:e82390.

40. Barker N, Huch M, Kujala P, van de Wetering M, Snippert HJ, van Es JH, Sato T, Stange DE, Begthel H, van den Born M, Danenberg E, van den Brink S, Korving J, et al. Lgr5(+ve) stem cells drive self-renewal in the stomach and build long-lived gastric units in vitro. Cell Stem Cell. 2010; 6:25-36.

41. Schepers AG, Snippert HJ, Stange DE, van den Born M, van Es JH, van de Wetering M, Clevers H. Lineage tracing reveals Lgr5+ stem cell activity in mouse intestinal adenomas. Science. 2012; 337:730-735.

42. Barker N, Ridgway RA, van Es JH, van de Wetering M, Begthel H, van den Born M, Danenberg E, Clarke AR, Sansom OJ, Clevers H. Crypt stem cells as the cells-oforigin of intestinal cancer. Nature. 2009; 457:608-611.

43. Qiao XT, Gumucio DL. Current molecular markers for gastric progenitor cells and gastric cancer stem cells. J Gastroenterol. 2011; 46:855-865.

44. Leushacke M, Barker N. Lgr5 and Lgr6 as markers to study adult stem cell roles in self-renewal and cancer. Oncogene. 2012; 31:3009-3022.

45. Zhao Y, Feng F, Zhou YN. Stem cells in gastric cancer. World J Gastroenterol. 2015; 21:112-123.

46. Zheng Y, Wang L, Zhang JP, Yang JY, Zhao ZM, Zhang $\mathrm{XY}$. Expression of p53, c-erbB-2 and Ki67 in intestinal metaplasia and gastric carcinoma. World J Gastroenterol. 2010; 16:339-344.

47. Leung WK, Wu MS, Kakugawa Y, Kim JJ, Yeoh KG, Goh KL, Wu KC, Wu DC, Sollano J, Kachintorn U, Gotoda T, Lin JT, You WC, et al. Screening for gastric cancer in Asia: current evidence and practice. Lancet Oncol. 2008; 9:279-287.

48. Tava F, Luinetti O, Ghigna MR, Alvisi C, Perego M, Trespi E, Klersy C, Fratti C, Fiocca R, Solcia E. Type or extension of intestinal metaplasia and immature/atypical "indefinitefor-dysplasia" lesions as predictors of gastric neoplasia. Hum Pathol. 2006; 37:1489-1497.

49. Dixon MF, Genta RM, Yardley JH, Correa P. Classification and grading of gastritis. The updated Sydney System. International Workshop on the Histopathology of Gastritis, Houston 1994. Am J Surg Pathol. 1996; 20:1161-1181.

50. Zhou Y, Wang Y, Wang S, Shen L. Hyperglycemia promotes human gastric carcinoma progression via aquaporin 3. Dig Dis Sci. 2015; 60:2338-2345. 